\title{
A busca da visão de Deus e o ouvir a sua palavra no Antigo Israel (síntese da colocação feita no Seminário em Homenagem ao Prof. Emanuel Bouzon)
}

\author{
Maria de Lourdes Corrêa Lima
}

\section{Introdução}

Surpreende que a busca de ver a Deus, tema de grande alcance teológico no Antigo Testamento, ocorra exatamente no contexto da fé israelita, que, por princípio, proíbe qualquer representação plástica de Deus. Por outro lado, em outras tradições bíblicas, o foco se concentra no ouvir e não no ver a Deus. A compreensão de cada uma destas perspectivas e a tentativa de conjugá-las numa visão de síntese é o escopo da presente contribuição.

\section{O ver a Deus}

A proibição de imagens de Deus diferencia Israel das culturas de seu entorno. Alguns estudiosos pretendem que tal proibição só se teria dado em tempos pós-exílicos, quando se impôs o javismo monoteísta. ${ }^{1}$ As expressões "ver, contemplar" YHWH no santuário (cf. S1 11,7; 27,4; 42,3; 63,3) são, neste contexto, consideradas em relação a uma possível imagem de Deus no Templo, cuja existência seria sinalizada, por exemplo, pela referência a YHWH que se encontra sobre o trono dos querubins (cf. 1Sm 4,4; $1 \mathrm{Sm} \mathrm{6,2;}$

1 Cf. O. Loretz, Ugarit und die Bibel. Kanaanäische Götter und Religion im Alten Testament, Darmstadt 19962, 211-214. 
S1 80,2) ou pela menção do carro (do trono) de Deus (cf. Ez 1,4-15; 10,14). Esta tese foi muito criticada em virtude da falta de dados empíricos que a comprovassem. Ao menos na ortodoxia do antigo Israel, atesta-se somente a presença de adornos plásticos no culto, não de uma imagem de YHWH (cf. Nm 21,4-9; 2Rs 18,4; Ex 25,18; 2Rs 21,2-7; 23,4-7). Por outro lado, numerosas passagens bíblicas criticam ou dão novo sentido às estelas cúlticas erigidas pelos patriarcas ao Deus dos pais (cf. Dt 12,3; 27,1-8), como que a indicar sua liceidade somente em épocas antigas. Isto é confirmado pela ausência de dados arqueológicos que atestassem uma representação de YHWH na religião israelita oficial. ${ }^{2}$

A proibição de imagens cúlticas de YHWH não é explicada nos textos vétero-testamentários, mas pode ser entendida pela correlação existente entre os dois primeiros mandamentos (cf. Ex 20,3.4-5; Dt 5,7-10). Procura preservar a absoluta transcendência de YHWH e inculcar sua exclusiva adoração como Deus de Israel. Tal medida foi significativa por evitar a introdução de elementos espúrios na fé israelita.

\section{A procura da visão de Deus}

A par da proibição das imagens de YHWH, diversos textos referem a possibilidade de ver a Deus (cf. Jz 13,22; Is 6,5) ou ver sua "face" (cf. Ex 33,20 ), ou vê-lo "face a face" (cf. Gn 32,31), embora sempre sob a ameaça da morte.

O termo "face" (panîm) não só indica o rosto de alguém, em sentido físico (cf. Gn 31,2.5), ou em seu interior (cf. 1Sm 1,18; Gn 40,7), mas ex-

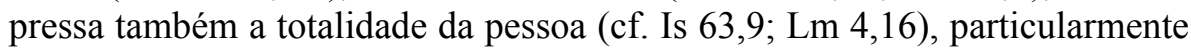
sob o aspecto de relacionamento interpessoal. Aplicado a Deus, designa-o como ser em relação com o ser humano. O desejo de ver a Deus é, nesse sentido, a busca pela sua presença e pela comunhão com Ele. ${ }^{3}$

Ilustra de modo significativo esta procura o pedido de Moisés, em Ex 33, que é mais bem compreendido dentro do contexto dos capítulos 32 a 34 . Tendo subido a montanha, Moisés afasta-se por longo tempo do povo (cf. Ex $32,1)$. Sem o mediador da palavra divina, o povo pede a Aarão um substituto

\footnotetext{
2 Sobre as representações encontradas em Kuntillet 'Ajrud e em Khirbet El-Qom, tratar-se-ia de um poste sagrado, não necessariamente representativo de YHWH ou pelo menos a atestação de um culto sincrético que teria tido lugar em santuários marginais. Cf. H.-D. Preuss, Theologie des Alten Testaments, I, Stuttgart, 1991, 124; E.M. Curtis, "Idol, Idolatry", in D.N. Freedman (ed.), The Anchor Bibel Dictionary (ABD), III, New York, 1992, 380.

3 Cf. H. Simian-Yofre, "panîm", in ThWAT, VI, 638-639.
} 
que evocasse a presença de Deus, a imagem de um bezerro. Embora a exegese atual demonstre que o bezerro aqui não seria uma imagem idolátrica, mas um pedestal indicar a presença invisível do Senhor, ${ }^{4}$ os redatores do texto interpretam-no como uma forma de idolatria. De fato, ele é chamado de "deus" e, ao vê-lo, Moisés o destrói (cf. Ex 32,20). A presença de Deus não se fará por nenhum artefato, mas o Senhor confirma o próprio Moisés como guia do povo (cf. Ex 32,34; 33,1) e garante sua presença através de seu "mensageiro" (cf. Ex 32,34; 33,2). No texto, este misterioso "mensageiro" parece ser, na realidade, uma forma de designar a presença velada de Deus (cf. Ex 32,21.25.30; 33,3.5). Para Moisés, contudo, Deus tem uma presença imediata: fala com ele "face a face" (cf. Ex 33,11). E lhe garante: "minha face irá contigo" (v. 12.15-16). Ele mesmo o acompanhará. Moisés, no entanto, pede mais: pede para "ver a glória" de Deus (v. 18). Deus responde indicando três formas de sua presença (v. 18-23), nas quais Moisés experimentará a glória de Deus. Mas o mais próprio dela ele não poderá ver: Moisés verá a Deus somente "de costas" (v. 23). Indica-se desse modo a transcendência divina, à qual nenhum ser humano pode ter pleno acesso. ${ }^{5}$

\section{A teologia da palavra e a visão de Deus}

Um dos pontos centrais da teologia do Deuteronômio e da Obra Histórica Deuteronomista, a centralização do culto em Jerusalém, visava elevar espiritualmente a religião. ${ }^{6}$ Aqui o templo, diferentemente das antigas representações, não é mais visto como morada de Deus (cf. Sl 27,4-6; 46,4; 74,2; $76,3)$, concepção esta que não deixava de oferecer perigos à fé. Para criar uma certa distância entre o lugar físico e a pessoa de Deus, ele é apresentado como morada do seu "Nome". Assim, à guisa de exemplo, quando tradições antigas referem o templo como casa de Deus, a teologia deuteronomista não deixa de oferecer-lhes uma correção, indicando ser o templo uma casa construída "para o nome de Deus" (1Rs 3,2; 5,17.19; 8,17-20.44.48), ou como casa onde o povo pode rezar a Deus, que, contudo, "mora nos céus" (1Rs 8,27.39). Assim também diz Dt 26,15: "Inclina-te da tua morada santa, do

4 Cf. R. Albertz, Historia de la religión de Israel em tiempos del Antiguo Testamento, I, Madrid 1999, 168 (original alemão 1992). Ainda H. Ringgren, “"egel”, in ThWAT, V, 10561061.

5 B.S. Childs, Il libro dell'Esodo. Commentario critico-teologico, Casale Monferrato, 1995, 598 (original inglês 1974).

6 Cf. M. Weinfeld, Deuteronomy and the Deuteronomic School, Winona Lake, 1992, 191209, esp. 191-194. 
céu, e abençoa o teu povo Israel...". Enquanto a teofania no Sinai fora acompanhada, em Ex 19,11-20, por uma série de elementos visuais, o texto paralelo de Dt 4,36 elimina-os e enfatiza: "dos céus Ele te fez ouvir a sua voz". Com isto, substitui-se o "ver" pelo "ouvir" (cf. 4,32-33; 5,22-26 e especialmente 4,10-12).

Em outras palavras, a presença de Deus, para a teologia deuteronômica-deuteronomista, se dá de modo privilegiado na sua palavra (cf. Dt 6,4-7: "Ouve, Israel"). Deste modo, se de um lado enfatiza-se a transcendência divina, de outro, valoriza-se mais claramente a fé enquanto se prescinde da visão.

\section{Conclusão}

A procura da face de Deus indica o desejo da proximidade de sua presença. O termo panîm, neste contexto, serve para evitar tanto a materialização através das imagens como uma transcendência divina que chegasse a afastá-lo demasiadamente. Ele garante a um tempo a proximidade e a distância e, com isto, caminha em parte na linha teológica da proibição das imagens de Deus, enquanto esta tem o mesmo escopo de não comprometer a transcendência divina.

Por outro lado, ouvir a palavra de YHWH substitui, na tradição deuteronômico-deuteronomista, a procura de "ver a sua face". Visando a eliminação de qualquer forma de idolatria, tira o foco da visão para localizá-lo na audição. Tal concepção exigirá uma purificação das antigas formas de busca de relacionamento com Deus. O Senhor habita no céu; aqui e agora se pode, contudo, realmente ter a sua presença através do ouvir obediente de sua palavra, que substitui a imagem (cf. Dt 4,9-20).

Tanto na procura da visão como no chamado a ouvir, trata-se, em última instância, do desejo de encontro com Deus. Este, embora mais fortemente expresso pela analogia visual, não é ausente da concepção auditiva. Ao contrário, sendo já na vida de Israel, experiência real de contato com Deus, a palavra, no entanto, ao tomar o lugar da imagem, constitui-se igualmente em meio propulsor para um mais pleno contato com a transcendência divina, expresso de modo mais claro pela analogia visual. O Novo Testamento não só levará ao máximo esta expectativa vétero-testamentária como também a mostrará plenamente realizada, embora ainda em tensão escatológica. Pois o Deus a quem ninguém "jamais viu" $(J o$ 1,18) pode ser ouvido e visto no Verbo encarnado (cf. Jo 1,14; 14,9). Jesus Cristo é cantado como "imagem do Deus invisível" $(\mathrm{Cl} 1,15)$. Por outro lado, aguarda-se a consu- 
mação de todo o desejo de comunhão, quando, na glória, "seremos semelhantes a Ele, porque o veremos como Ele é" (1Jo 3,2).

Maria de Lourdes Corrêa Lima

Professora do Departamento de Teologia da PUC-Rio

Doutora em Teologia Bíblica pela Pontifícia Universidade Gregoriana

(Roma) 